\title{
Pathological and Biological Differences Between Screen-Detected and Interval Ductal Carcinoma in situ of the Breast
}

\author{
Marnix A. de Roos, MD, ${ }^{1}$ Bert van der Vegt, $\mathrm{MD},{ }^{2}$ Jaap de Vries, MD, PhD, ${ }^{1}$ \\ Jelle Wesseling, $\mathrm{MD}, \mathrm{PhD},{ }^{2}$ and Geertruida $\mathrm{H}$. de Bock, $\mathrm{PhD}^{3}$
}

\footnotetext{
${ }^{1}$ Department of Surgical Oncology, University Medical Center Groningen, University of Groningen, Hanzeplein 1, PO Box 30001, 9700, RB, Groningen, The Netherlands

${ }^{2}$ Department of Pathology, University Medical Center Groningen, University of Groningen, Hanzeplein 1, PO Box 30001, 9700, RB, Groningen, The Netherlands

${ }^{3}$ Department of Epidemiology, University Medical Center Groningen, University of Groningen, Hanzeplein 1, PO Box 30001, 9700, RB, Groningen, The Netherlands
}

\begin{abstract}
Background: The incidence of ductal carcinoma in situ (DCIS) has risen dramatically with the introduction of screening mammography. The aim was to evaluate differences in pathological and biological characteristics between patients with screen-detected and interval DCIS.

Methods: From January 1992 to December 2001, 128 consecutive patients had been treated for pure DCIS at our institute. From these, 102 had been attending the Dutch breast cancer screening program. Sufficient paraffin-embedded tissue was available in 74 out of the 102 cases to evaluate biological marker expression (Her2/neu, ER, PR, p53 and cyclin D1) on tissue microarrays (TMA group). Differences in clinicopathological characteristics and marker expression between screen-detected and interval patients were evaluated. Screen-detected DCIS was classified as DCIS detected by screening mammography, when the two-year earlier examination failed to reveal an abnormality. Interval patients were classified as patients with DCIS detected within the two-year interval between two subsequent screening rounds.

Results: Screen-detected DCIS was related with linear branching and coarse granular microcalcifications on mammography $(\mathrm{p}<.001)$ and with high-grade DCIS according to the Van Nuys classification $(\mathrm{p}=.025)$. In univariate analysis, screen-detected DCIS was related with Her2/neu overexpression (odds ratio $[\mathrm{OR}]=6.5 ; 95 \% \mathrm{CI} 1.3-31.0 ; \mathrm{p}=.020$ ), and interval DCIS was associated with low-grade (Van Nuys, OR $=7.3 ; 95 \%$ CI 1.6-33.3; $\mathrm{p}=$ $.010)$ and $\mathrm{PR}$ positivity $(\mathrm{OR}=0.3 ; 95 \% \mathrm{CI} 0.1-1.0 ; \mathrm{p}=.042)$. The multivariate analysis displayed an independent relation of Her2/neu overexpression with screen-detected DCIS (OR $=12.8 ; 95 \%$ CI $1.6-104.0 ; \mathrm{p}=.018$ ).

Conclusions: These findings suggest that screen-detected DCIS is biologically more
\end{abstract} aggressive than interval DCIS and should not be regarded as overdiagnosis.

Key Words: Breast neoplasm-Ductal carcinoma in situ-Screening-Biological markers-Immunohistochemistry.

Received November 5, 2006; accepted February 7, 2007; published online: April 24, 2007.

Address correspondence and reprint requests to: Marnix A. de Roos, MD; E-mail: m.a.j.de.roos@chir.umcg.nl

Published by Springer Science+Business Media, LLC @ 2007 The Society of Surgical Oncology, Inc.
With the introduction of widespread screening mammography, the incidence rates of ductal carcinoma in situ (DCIS) have risen dramatically in Western Europe and North America. ${ }^{1-3}$ DCIS now accounts for nearly $20 \%$ of all screen-detected breast malignancies. ${ }^{4}$ 
As a consequence, treating physicians are confronted with a cumulative caseload because it is not known how many women with screen-detected DCIS will develop an invasive carcinoma in their lifetimes. The proportion of untreated cases of DCIS that would progress to invasive malignancy has been difficult to evaluate, because DCIS is usually excised when detected. Because DCIS is a nonobligatory precursor to invasive carcinoma, and, therefore, has a relatively benign nature, screen-detected DCIS has been argued to represent an overdiagnosis. ${ }^{5,6}$ This argument is supported by autopsy studies in which the median prevalence of DCIS was $8.9 \%$, suggesting some cases do not progress to clinically significant lesions in a patient's lifetime. ${ }^{7}$ On the contrary, patients with DCIS treated with biopsy alone in the premammography era had a higher rate of subsequent occurrences (14-50\%) of invasive breast cancer than expected. ${ }^{8,9}$ Large clinical trials, in which patients had been treated with lumpectomy alone, have also indicated that DCIS can recur as invasive ductal carcinoma. ${ }^{10,11}$

Screen-detected DCIS is more often presented as linear branching microcalcifications on mammography than symptomatic DCIS. ${ }^{12}$ The screen-detected group in the previously mentioned study had a larger proportion of patients with comedocarcinoma. Therefore, it was suggested that linear branching microcalcifications were related with a more aggressive type of DCIS. ${ }^{12}$ This is confirmed in other reports that have indicated that linear branching microcalcifications on mammography are associated with high grade DCIS. ${ }^{13,14}$

We believe that screen-detected DCIS is more often associated with suspicious microcalcifications representing high-grade DCIS, which has been detected before it has had the chance to progress to invasive cancer. Therefore, it is hypothesized that screen-detected DCIS is biologically more aggressive than interval DCIS. To compare screen-detected DCIS with interval DCIS in such a retrospective study, the clinicopathological and biological characteristics of both groups were evaluated for differences. Screendetected DCIS was classified as DCIS detected by screening mammography, when the examination from two years earlier failed to reveal an abnormality. Interval DCIS was classified as DCIS detected within the two-year interval between two subsequent screening rounds, when the earlier examination failed to reveal an abnormality. Age, tumor size, and pathological grade were studied for their known relation with local recurrence. Finally, the expression of established prognostic biomarkers in breast cancer was studied by immunohistochemistry for estrogen receptor (ER), progesterone receptor (PR), Her2/neu, p53, and cyclin D1.

\section{PATIENTS AND METHODS}

\section{Patients and Tumors}

The Dutch screening program for breast cancer has been gradually implemented in the North Netherlands since 1991. It offered biennial mammography to women 50-69 years old, and since 1999 women 70-74 years old have also been included. Women received mammography in the cranio-caudal and medio-latero-oblique direction for each breast. Two radiologists evaluated the mammograms by a double independent reading.

From January 1992 to December 2001, 128 consecutive patients were treated for pure DCIS at our institution. To identify patients for inclusion in the study, all women who had actually attended the screening program at least two subsequent rounds with a two-year interval at the time of diagnosis were considered as attenders. Patients who had skipped one or more screening rounds previous to the diagnosis and patients who had not been attending the program at all were considered nonattenders. Patients' records were checked to obtain this information, and if there was no information regarding the participation of the screening program at the time of diagnosis the general practitioner was consulted. Out of the 128 consecutive patients, 102 attenders and 26 nonattenders could be identified. For immunohistochemistry, patients were selected on the availability of sufficient paraffin-embedded tissue. Thirteen out of the 26 nonattenders and 74 out of the 102 attenders remained, respectively, for evaluation of Her2/neu overexpression, estrogen receptor (ER) expression, progesterone receptor (PR) expression, p53 expression, and cyclin D1 expression using tissue microarray analysis as part of a project protocol that had been approved by the medical ethics committee. The patients in the study-group $(\mathrm{n}=74)$ were divided into two groups. Patients with DCIS that had been detected by screening mammography were classified as screen-detected patients, when the examination two years earlier failed to reveal an abnormality $(\mathrm{n}=$ 54). Patients with DCIS that had been detected within the two-year interval between two subsequent screening rounds were classified as interval patients, when the earlier examination failed to reveal an abnormality $(\mathrm{n}=20)$. 
TABLE 1. Antigen retrieval methods and antibodies

\begin{tabular}{|c|c|c|c|c|c|c|c|c|}
\hline Antibody & Clone & Supplier & Dilution & Antigen retrieval & $\begin{array}{l}\text { Secondary } \\
\text { antibody }\end{array}$ & Supplier & $\begin{array}{l}\text { Tertiary } \\
\text { antibody }\end{array}$ & Supplier \\
\hline ER & $6 \mathrm{~F} 11$ & Ventana & a & Tris/HCL $0.1 \mathrm{M}(\mathrm{pH} 9.5) 30^{\prime} 98^{\circ} \mathrm{C}$ microwave & RAMBIO & Dako & SARBIO & Dako \\
\hline PR & $1 \mathrm{~A} 6$ & Ventana & a & Tris/HCL $0.1 \mathrm{M}(\mathrm{pH} 9.5) 30^{\prime} 98^{\circ} \mathrm{C}$ microwave & RAMBIO & Dako & SARBIO & Dako \\
\hline $\mathrm{Her}-2 / \mathrm{Neu}$ & CB11 & Ventana & a & Tris/HCL $0.1 \mathrm{M}(\mathrm{pH} 9.5) 30^{\prime} 98^{\circ} \mathrm{C}$ microwave & RAMBIO & Dako & SARBIO & Dako \\
\hline p53 & BP-53-12-1 & Biogenix & $1: 800$ & Tris/HCL $0.1 \mathrm{M}(\mathrm{pH} 9.5) 30^{\prime} 98^{\circ} \mathrm{C}$ microwave & RAMBIO & Dako & SARBIO & Dako \\
\hline Cyclin D1 & SP4 & Neomarkers & $1: 50$ & Tris/HCL $0.1 \mathrm{M}(\mathrm{pH} 9.5) 30^{\prime} 98^{\circ} \mathrm{C}$ microwave & RAMBIO & Dako & SARBIO & Dako \\
\hline
\end{tabular}

\section{Mammography and Pathological Assessment}

Mammographic and pathological characteristics were derived from mammography and pathological reports, respectively. Data were delivered and evaluated anonymously. If data were missing, mammography and pathological slides were reevaluated. Mammographic appearances were scored as microcalcifications, a mass, a combination of the two, or as occult. Microcalcifications were scored as fine granular, coarse granular, or as linear branching. Pathological size had been estimated, and the grade had been scored according to the European Pathologists Working Group (EPWG ${ }^{15}$ ) and according to the Van Nuys classification. ${ }^{16}$

\section{Tissue Microarray Construction}

Slides from all blocks were evaluated for representative areas with DCIS, and tissue microarrays were prepared as described earlier. ${ }^{17}$ In brief, the most representative area of DCIS was marked on the original hematoxylin and eosin (H\&E) stained section. With this marked section as an orientation, three $0.6-\mathrm{mm}$ punches were taken from the selected area in the donor blocks and mounted in a recipient block containing approximately 110 biopsies, using a manual tissue microarray device (Beecher Instruments, Silver Springs, MD). The presence of DCIS in the arrayed samples was verified on hematoxylin eosin stained sections.

\section{Immunohistochemistry}

For immunohistochemistry, $3 \mu \mathrm{m}$ sections of the paraffin-embedded tissue arrays were deparaffinized in 2 changes of xylene for 5 minutes each and gradually rehydrated through changes of graded ethanol from $100 \%$ to distilled water. Antigen retrieval methods and antibodies are summarized in Table 1. The endogenous peroxidase reaction was blocked by incubating the sections in $3 \%$ perhydrol for 30 minutes. Primary antibodies were diluted in phosphatebuffered saline (PBS) containing 1\% bovine serum albumin and incubated at room temperature for 1 hour. Samples were then washed in PBS and incubated with secondary and tertiary antibodies. For visualization of the antibody-antigen complex, the diaminobenzidine tetrahydrochloride/peroxidase reaction was used. After a final wash with distilled water, sections were counterstained with hematoxylin. Sections were dehydrated through rising concentrations of ethanol and mounted. Immunohistochemistry was successful in 81/87 cases for Her2/neu staining, 73/87 cases for ER staining, $71 / 87$ for PR and cyclin D1 staining, and 70/87 for p53 staining.

\section{Evaluation of Immunohistochemical Staining}

All slides stained for molecular markers were read by two authors (MdR and BvdV). The slides were randomly reviewed by a third author (JW) and in case of disagreement between the other two authors. ER, PR, and p53 were graded based on the percentage of cells showing positive nuclear staining in the ducts with DCIS. ER and PR were considered positive if nuclear staining was present in $\geq 10 \%$ of the cases, and p53 was considered positive in case of a substantial percentage of positively stained nuclei $(>30 \%)$. Her $2 /$ neu expression was graded as recommended by the HercepTest ${ }^{\mathrm{TM}}$ scoring guidelines: 0 : no staining at all or membrane staining in $<10 \%$ of tumor cells; $1+$ : a faint/barely perceptible partial membrane staining in $>10 \%$ of the tumor cells; $2+$ : weak to moderate complete membrane staining in $>10 \%$ of tumor cells; $3+$ : strong complete membrane staining in $>10 \%$. Her-2/neu was considered to be overexpressed if the score was $3+$. Cyclin D1 expression was scored using a semiquantitative system as described by Vos et al. ${ }^{18}$ This system was based on the staining intensity scored as 0 (none), 
1 (weak), 2 (moderate), and 3 (strong), and the percentage of positive tumor cell nuclei scored as $0(0 \%)$, $1(1-25 \%), 2(25-50 \%), 3(50-75 \%)$, and $4(>75 \%)$. The cyclin D1 staining score was calculated as the sum of the intensity and the percentage of positive tumor cells.

\section{Statistical Analysis}

Differences in clinicopathological characteristics between screen-detected and interval patients with DCIS in the study group, and between the study group and the excluded group of patients were analyzed by chi-square analysis. Differences in clinicopathological and biological characteristics between the study group and the nonattenders were also analyzed by chi-square analysis. Differences in age were tested by using the Mann-Whitney $U$ test. Univariate analyses, investigating differences in pathological and biological features, was performed by logistic regression, using screen detection as a dependent variable. Multivariate analyses were performed with a logistic-regression model. The elimination of variables in a stepwise manner identified the statistically significant pathological and biological parameters. A p value of $\leq .050$ was considered as significant. All calculations were performed with SPSS 12.01 (SPSS inc., Chicago, IL).

\section{RESULTS}

Table 2 shows the clinicopathological characteristics of the patients in the study group $(n=74)$. Screen-detected DCIS was less often symptomatic than interval DCIS $(\mathrm{p}<.001)$. Five patients $(25 \%)$ in the interval group had no objective signs on presentation; all patients had felt a lump in the breast that could not be verified on clinical examination. On mammography, microcalcifications were more often seen in screen-detected DCIS ( $p=.002)$. Screen-detected DCIS was more often presented as linear branching (44.9\%) and coarse granular (55.9\%) microcalcifications than interval DCIS $(\mathrm{p}<0.001)$. Highgrade DCIS (Van Nuys, 53.1\%, $\mathrm{p}=.025$ ) was also more often observed in screen-detected DCIS.

Differences in clinicopathological characteristics between the study-group $(n=74)$ and the group of patients that had been excluded $(n=28)$ because of insufficient paraffin embedded tissue are outlined in Table 3. There was no marked difference in age, microcalcifications, tumor size, and pathological grade according to the EPWG classification between
TABLE 2. Clinicopathological characteristics of the patients in the study group and differences between screen-detected and interval patients

\begin{tabular}{|c|c|c|c|}
\hline $\begin{array}{l}\text { Clinicopathological } \\
\text { characteristics }\end{array}$ & $\begin{array}{l}\text { Screen-detected } \\
\mathrm{n}=54\end{array}$ & $\begin{array}{l}\text { Interval } \\
\mathrm{n}=20\end{array}$ & p-value ${ }^{a}$ \\
\hline Age (mean), years & 58.9 & 60.7 & .187 \\
\hline Family history of breast cancer & & & .055 \\
\hline Yes & $8(14.8)$ & $7(35)$ & \\
\hline No & $46(85.2)$ & $13(65)$ & \\
\hline \multicolumn{4}{|l|}{ Signs } \\
\hline Palpable mass & $5(9.3)$ & $6(30)$ & $<.001$ \\
\hline Nipple discharge & $2(3.7)$ & $9(45)$ & \\
\hline Mastodynia & $1(1.9)$ & $0(0)$ & \\
\hline No objective signs & $46(85.1)$ & $5(25)$ & \\
\hline Mammography & & & .002 \\
\hline Microcalcifications & $46(85.2)$ & $10(50)$ & \\
\hline Mass & $2(3.7)$ & $6(30)$ & \\
\hline Combination mc's and mass & $6(11.1)$ & $4(20)$ & \\
\hline Microcalcifications & & & $<.001$ \\
\hline Linear branching & $22(44.9)$ & $4(28.6)$ & \\
\hline Coarse granular & $27(55.1)$ & $4(28.6)$ & \\
\hline Fine granular & $0(0)$ & $6(42.9)$ & \\
\hline Mammographic size & & & .183 \\
\hline$\leq 2 \mathrm{~cm}$ & $21(42.6)$ & $12(60)$ & \\
\hline$>2 \mathrm{~cm}$ & $33(57.4)$ & $8(40)$ & \\
\hline BCS & $23(42.6)$ & $8(40)$ & .841 \\
\hline Mastectomy & $31(57.4)$ & $12(60)$ & \\
\hline Tumor size & & & .787 \\
\hline$<16 \mathrm{~mm}$ & $19(35.2)$ & $6(30)$ & \\
\hline $16-40 \mathrm{~mm}$ & $17(31.5)$ & $8(40)$ & \\
\hline$>40 \mathrm{~mm}$ & $18(33.3)$ & $6(30)$ & \\
\hline Grade (EPWG) & & & .229 \\
\hline 1 & $4(7.5)$ & $4(20)$ & \\
\hline 2 & $29(53.7)$ & $11(55)$ & \\
\hline 3 & $21(38.9)$ & $5(25)$ & \\
\hline Grade (Van Nuys) & & & .025 \\
\hline 1 & $4(7.4)$ & $6(30)$ & \\
\hline 2 & $24(44.4)$ & $9(45)$ & \\
\hline 3 & $26(53.1)$ & $5(25)$ & \\
\hline
\end{tabular}

Mann-Whitney U test.

Values between parentheses are percentages.

BCS, breast conserving surgery; EPWG, European Pathologist Working Group.

${ }^{a}$ Chi-square analyses.

both groups. The excluded group of patients represented a relatively large proportion of low-grade DCIS according to the Van Nuys classification ( $\mathrm{p}<$ .001) in comparison with the TMA group.

There were no differences in clinicopathological and biological characteristics between the study group and the nonattenders $(n=13)$, except the fact that nonattenders were younger than the patients in the study group (55.9 years versus 59.6 years; $\mathrm{p}=.042$ ).

Table 4 displays the relation among pathological characteristics, biological marker expression, and mode of detection in the study group. Univariate logistic regression analysis indicated that in screendetected DCIS Her2/neu is more often overexpressed (odds ratio $[\mathrm{OR}]=6.5 ; 95 \%$ confidence interval $[\mathrm{CI}]$ $1.3-31.0 ; \mathrm{p}=.020)$. Interval DCIS is more frequently 
TABLE 3. Comparison of clinicopathological characteristics between the study group and the group of patients that were excluded because of insufficient paraffin-embedded tissue

\begin{tabular}{llll}
\hline $\begin{array}{l}\text { Clinicopathological } \\
\text { characteristics }\end{array}$ & $\begin{array}{l}\text { Study group } \\
\mathrm{n}=74\end{array}$ & $\begin{array}{l}\text { Excluded } \\
\mathrm{n}=28\end{array}$ & $\mathrm{p}^{\text {-value }}$ \\
\hline $\begin{array}{l}\text { Age (mean) } \\
\text { Microcalcifications }(\mathrm{n}=86)\end{array}$ & 59.6 & 61.5 & .381 \\
$\quad \begin{array}{l}\text { Linear branching } \\
\text { Coarse granular }\end{array}$ & $26(41.3)$ & $5(25)$ & .063 \\
$\quad \begin{array}{l}\text { Fine granular } \\
\text { Tumor size }\end{array}$ & $6(9.5)$ & $6(49)$ & \\
$\quad<16 \mathrm{~mm}$ & & & .458 \\
$16-40 \mathrm{~mm}$ & $25(33.8)$ & $7(25)$ & \\
$>40 \mathrm{~mm}$ & $25(33.8)$ & $9(32.1)$ & \\
Grade (EPWG) & $24(32.6)$ & $12(42.9)$ & \\
1 & & & .184 \\
2 & $8(10.8)$ & $6(21.4)$ & \\
3 & $40(54.1)$ & $10(35.7)$ & \\
Grade (Van Nuys) & $26(35.1)$ & $12(42.9)$ & \\
1 & & & $<.001$ \\
2 & $10(13.5)$ & $15(53.6)$ & \\
3 & $33(44.6)$ & $6(21.4)$ & \\
\hline
\end{tabular}

Mann-Whitney U test.

Values between parentheses are percentages.

EPWG, European Pathologist Working Group.

${ }^{\text {a }}$ Chi-square analyses.

positive for PR staining (OR $=0.3$; 95\% CI 0.1-1.0; $\mathrm{p}=.042)$ and is related to low pathological grade according to the Van Nuys classification $(\mathrm{OR}=7.3$; 95\% CI 1.6-33.3; $\mathrm{p}=.010)$. In multivariate logistic regression, including pathological grade according to the EPWG and Van Nuys classification, Her2/neu overexpression and PR expression in the model, Her2/neu overexpression was the only independent indicator for screen-detected DCIS (OR $=12.8 ; 95 \%$ CI $1.6-104.0 ; \mathrm{p}=.018)$.

\section{DISCUSSION}

Approximately 1 in every 1300 screening mammography examinations leads to a diagnosis of DCIS. ${ }^{4}$ Data from a large trial and service screening programs in the United Kingdom, the Netherlands, Australia, and the United States have demonstrated that a woman attending prevalence screen has a 19 times greater chance of having a progressive DCIS or an invasive tumor diagnosed than of having a nonprogressive DCIS diagnosed. ${ }^{19}$ It is questioned what to do with the high detection rate of screen-detected DCIS. It was hypothesized that screen-detected DCIS is biologically more aggressive than interval DCIS because suspicious microcalcifications, detected by the screening program, will probably more frequently represent high-grade DCIS. Therefore screen-detected DCIS was characterized pathologically and biologically to determine whether screen-detected DCIS differed from interval DCIS. The results of this study indicate that screen-detected DCIS is pathologically $(\mathrm{OR}=7.3 ; 95 \%$ CI $1.6-33.3 ; \mathrm{p}=.010)$ and biologically $(\mathrm{OR}=12.8 ; 95 \% \mathrm{CI} 1.6-104.0 ; \mathrm{p}=.018)$ more aggressive than interval DCIS. Indeed screendetected DCIS was related with more suspicious microcalcifications $(\mathrm{p}<.001)$. DCIS detected by a prevalence screen was pathologically and biologically comparable to DCIS detected in later rounds (data not shown) suggesting prevalence and incident cases to both be of clinical relevance.

The relative incidence of high-grade DCIS in our series of screen-detected patients was $53 \%$, which is comparable to the incidence of high-grade DCIS in a screening population from the Netherlands Cancer Institute (47\%). ${ }^{20}$ Much data point out that poorly differentiated or high-grade DCIS lesions have a greater potential to progress to invasive disease than low-grade DCIS. ${ }^{21}$ High grade is also an independent risk factor of local recurrence after lumpectomy for DCIS, and approximately 50\% of these recurrences are invasive cancers. ${ }^{22,23}$ There are no studies available comparing screen-detected with interval DCIS in a group of patients that had all been attending the screening program. Reports on screen-detected DCIS regarding histopathological grade vary markedly describing a higher incidence of low grade, ${ }^{24}$ no difference, ${ }^{25}$ or a higher incidence of high grade ${ }^{12,26,27}$ in screen-detected DCIS. In these reports screen-detected DCIS is compared to symptomatic DCIS or to DCIS detected in a period before the screening program was introduced. In the present study, a higher incidence of high-grade lesions, which were classified according Van Nuys $(\mathrm{OR}=7.3$; 95\% CI 1.6-33.3; $\mathrm{p}$ $=.010)$ classification, was found in screen-detected DCIS, indicating a higher malignant potential in screen-detected DCIS. These results are consistent with the results from the studies of Evans et al. ${ }^{26}$ and Kessar et al. ${ }^{27}$

DCIS lesions from patients in the study group were compared to DCIS lesions from patients who had not attended the screening program. Out of the 26 nonattenders, there were only 13 patients from whom sufficient paraffin-embedded tissue was available. Using chi-square analysis there were no differences in pathological and biological characteristics between the two groups. The difference in age could be explained by the fact that the nonattenders group also contained patients under 50-years of age. From these analyses it seems that DCIS in nonattenders is not pathologically and biologically more aggressive than DCIS in attenders of the screening program. 
TABLE 4. Univariate analysis of pathological and biological characteristics in screen-detected versus interval DCIS in the study group

\begin{tabular}{|c|c|c|c|c|c|}
\hline Pathological and biological features & Screen-detected $n=54$ & Interval $\mathrm{n}=20$ & OR by screen-detected & $95 \% \mathrm{CI}$ & p-value \\
\hline \multicolumn{6}{|l|}{ Tumor size } \\
\hline$<16 \mathrm{~mm}$ & $19(35.2)$ & $6(30)$ & 0.8 & 0.2 & 0.744 \\
\hline $16-40 \mathrm{~mm}$ & $17(31.5)$ & $8(40)$ & 1.1 & 0.2 & 0.827 \\
\hline$>40 \mathrm{~mm}$ & $18(33.3)$ & $6(30)$ & 1 & & \\
\hline \multicolumn{6}{|l|}{ Grade (EPWG) } \\
\hline 1 & $4(7.5)$ & $4(20)$ & 3.800 & 0.5 & 0.377 \\
\hline 2 & $29(53.7)$ & $11(55)$ & 1.703 & 0.7 & 0.124 \\
\hline 3 & $21(38.9)$ & $5(25)$ & 1 & & \\
\hline \multicolumn{6}{|l|}{ Grade (Van Nuys) } \\
\hline 1 & $4(7.4)$ & $6(30)$ & 7.3 & 1.6 & \\
\hline 2 & $24(44.4)$ & $9(45)$ & 1.6 & 0.5 & 0.416 \\
\hline 3 & $26(53.1)$ & $5(25)$ & 1 & 1.6 & 0.010 \\
\hline \multicolumn{6}{|l|}{ Her $2 /$ neu $(\mathrm{n}=68)$} \\
\hline Positive & $29(60.4)$ & $2(10)$ & 6.5 & $1.3-31.0$ & 0.020 \\
\hline \multirow{2}{*}{\multicolumn{6}{|c|}{$\mathrm{ER}(\mathrm{n}=62)$}} \\
\hline & & & & & \\
\hline Positive & $33(75)$ & $16(88.9)$ & 0.4 & & \\
\hline Negative & $11(25)$ & $2(11.1)$ & 1 & $0.1-1.9$ & 0.236 \\
\hline \multicolumn{6}{|l|}{$\mathrm{PR}(\mathrm{n}=60)$} \\
\hline Positive & $18(42.9)$ & $13(65)$ & 0.3 & & \\
\hline Negative & $24(57.1)$ & $5(35)$ & 1 & $0.1-1.0$ & 0.042 \\
\hline \multicolumn{6}{|l|}{$\mathrm{p} 53(\mathrm{n}=60)$} \\
\hline Positive & $10(24.4)$ & $4(21.1)$ & 0.8 & & \\
\hline Negative & $31(75.6)$ & $15(78.9)$ & 1 & $0.2-3.1$ & 0.776 \\
\hline \multicolumn{6}{|l|}{ Cyclin D1 $(\mathrm{n}=60)$} \\
\hline Positive & $29(69.1)$ & $13(72.2)$ & 0.9 & $0.3-2.9$ & 0.806 \\
\hline Negative & $13(30.9)$ & $5(27.8)$ & 1 & & \\
\hline
\end{tabular}

Univariate analysis using logistic regression.

Figures in parentheses are percentages.

OR, odds ratio; EPWG, European Pathologist Working Group; ER, estrogen receptor; PR, progesterone receptor. 95\% CI, 95\% confidence interval.

However, because of the very small number of patients in the nonattenders group no hard conclusions can be drawn.

Her2/neu overexpression has been found to correlate with various pathologic and biological factors believed to be associated with more aggressive behavior; high grade, presence of necrosis, ER and PR negativity, and overexpression of Ki-67 (indicating an increased proliferation rate) are features that are strongly related with $\mathrm{Her}-2 / \mathrm{neu}$ overexpression. ${ }^{28-30}$ The report of Walker et al. ${ }^{24}$ displayed a Her-2/neu expression of 59\% in symptomatic DCIS and of $42 \%$ in mammographically detected DCIS. Another study by Idvall et al. ${ }^{25}$ reported no difference in Her-2/neu expression between DCIS before and after introduction of mammographic screening. In this present study Her2/neu overexpression was the only independent feature to be related with screen-detected DCIS in multivariate analysis $(\mathrm{OR}=$ $12.8 ; 95 \%$ CI $1.6-104.0 ; \mathrm{p}=.018)$, which indicates a more aggressive profile of screen-detected DCIS when compared to interval DCIS.

Although the statistical methods used were univariate and multivariate analysis, the numbers in both groups are small, which explains the broad $95 \%$ CI. The small numbers are due to the selection of patients in this study for study period, attendance of screening rounds, and availability of sufficient paraffin-embedded tissue. Clearly, further studies with larger populations are needed to elucidate the relative significance of the Her2/neu overexpression in women with screen-detected DCIS. Although 28 out of 102 patients were excluded because of lack of sufficient paraffin-embedded tissue, there is no reason to assume that this exclusion results in a significant selection bias. Apart from pathological grade according to Van Nuys, there were no differences in clinicopathological characteristics between the study group and the group of excluded patients. The group of excluded patients displayed a relatively large amount of low-grade DCIS according to Van Nuys $(53.6 \%, \mathrm{p}<.001)$, which is mainly derived from the interval group ( $\mathrm{n}=10$, data not shown). If all patients would have been included the relation of pathological grade and probably Her2/neu expression with screen-detected patients would be even more significant. The inclusion of patients that actually took part in the screening program was 
necessary to analyze differences between screen-detected and interval DCIS, which, to our knowledge, has not been performed previously.

Expression of ER, p53, and cyclin D1 was not related to screen-detected or interval DCIS. There was, however, a relation between screen-detected DCIS and PR negativity in univariate analysis $(\mathrm{OR}=$ 0.288; 95\%CI 0.087-0.957; $\mathrm{p}=.042$ ). Other studies could not demonstrate a relation of screen-detected DCIS with the expression of the aforementioned markers. ${ }^{12,24,25}$ In a review by Boland et al. ${ }^{31}$ ER and PR positivity are related to low-grade DCIS, whereas p53 and cyclin D1 expression are associated with high grade. The fact that screen-detected DCIS is associated with PR negativity provides indirect evidence for the presence of a more aggressive tumor biology. Obviously, PR expression is related to Her2/neu expression, because PR expression was not significant in multivariate analysis.

Ultimately, the question is how we should interpret these findings. The authors think the results from this study represent no evidence to alter patient management and screening recommendations. Instead, they should rather be regarded as support of current clinical practice in DCIS of the breast. They confirm that every DCIS should be treated until we are able to identify DCIS that will progress to invasive cancer if left untreated.

In conclusion, since the advent of screening, the increased incidence of DCIS has raised concerns about the possibility of overdiagnosis of DCIS. This study has shown that screen-detected DCIS has a more aggressive tumor profile than interval DCIS. Therefore, screen-detected DCIS should not be regarded as an overdiagnosis per se, and every woman diagnosed with DCIS by mammographic screening should be treated properly according to existing guidelines or standards of care.

\section{ACKNOWLEDGMENTS}

This study has been supported by grant 544290 from the J.K. De Cock foundation, Groningen, The Netherlands. We would like to thank Dr. C.H. Thorp for his grammatical corrections and improvements of the manuscript.

\section{REFERENCES}

1. Voogd AC, Crommelin MA, van Repelaer Driel OJ, Nolthenius-Puylaart MC, van der Heijden LH, Coebergh JW. Trends in incidence and treatment of ductal carcinoma in situ of the breast in southeast Netherlands. Ned Tijdschr Geneeskd 2000; 14:659-63.

2. Levi F, Te VC, Randimbison L, La Vecchia C. Trends of in situ carcinoma of the breast in Vaud, Switzerland. Eur $J$ Cancer 1997; 33:903-6.

3. Ernster V, Barclay J, Kerlikowske K, Grady D, Henderson I Incidence of and treatment for ductal carcinoma in situ of the breast. JAMA 1996; 275:913-8.

4. Ernster VL, Ballard-Barbash R, Barlow WE, et al. Detection of ductal carcinoma in situ in women undergoing screening mammography. J Natl Cancer Inst 2002; 94:1546-54.

5. Jatoi I, Baum M. Mammographically detected ductal carcinoma in situ: are we over-diagnosing breast cancer? Surgery 1995; 118:188-21.

6. Thornton H. Consequences of breast screening. Lancet 2000; 356:1033.

7. Welch HG, Black WC. Using autopsy series to estimate the disease "reservoir" for ductal carcinoma in situ of the breast: how much more breast cancer can we find? Ann Intern Med 1997; 127:1023-8.

8. Page DL, Dupont WD, Rogers LW, Jensen RA, Schuyler PA. Continued local recurrence of carcinoma 15-25 years after a diagnosis of low grade ductal carcinoma in situ of the breast treated only by biopsy. Cancer $1995 ; 76: 1197-1200$.

9. Eusebi V, Foschini MP, Cook MG, Berrino F, Azzopardi JG. Long-term follow-up of in situ carcinoma of he breast with special emphasis on clinging carcinoma. Semin Diagn Pathol 1989; 6:165-73.

10. Fisher E, Dignam J, Tan-Chiu E, et al. Pathologic findings from the National Surgical Adjuvant Breast Project (NSABP) eight year update of Protocol B-17. Cancer 1999; 86:429-38.

11. Julien JP, Bijker N, Fentiman I, et al. Radiotherapy in breast conserving treatment for ductal carcinoma in situ: first results of the EORTC randomised phase III trial 10853. Lancet 2000; 355:528-33.

12. Evans A, Pinder S, Ellis I, et al. Screening-detected and symptomatic ductal carcinoma in situ: mammographic features with pathologic correlation. Radiology 1994; 191:237-40.

13. Stomper P, Conolly J. Ductal carcinoma in situ of the breast: correlation between mammographic calcification and tumor subtype. Am J Radiol 1992; 159:483-5.

14. de Roos MA, Pijnappel RM, Post WJ, de Vries J, Baas PC, Groote AD. Correlation between imaging and pathology of ductal carcinoma in situ of the breast. World J Surg Oncol 2004; 2:4.

15. Holland R, Peterse JL, Millis RR, et al. Ductal carcinoma in situ: a proposal for a new classification. Semin Diagn Pathol 1994; 11:167-80.

16. Silverstein MJ, Poller DN, Waisman JR, et al. Prognostic classification of breast ductal carcinoma in situ. Lancet 1995; 345:1154-7.

17. Kononen J, Bubendorf L, Kallioniemi A, et al. Tissue microarrays for high-throughput molecular profiling of tumor specimens. Nat Med 1998; 4:844-7.

18. Vos CB, Ter Haar NT, Peterse JL, Cornelisse CJ, van de Vijver MJ. Cyclin D1 gene amplification and overexpression are present in ductal carcinoma in situ of the breast. J Pathol 1999; 189:279-84.

19. Yen MF, Tabar L, Vitak B, Smith RA, Chen HH, Duffy SW. Quantifying the potential problem of overdiagnosis of ductal carcinoma in situ in breast cancer screening. Eur $J$ Cancer 2003; 39:1746-54.

20. Meijnen $\mathrm{Ph}$, Peterse JL, Oldenburg LA, Woerdeman LA, Rutgers EJ. Changing patterns in diagnosis and treatment of ductal carcinoma in situ of the breast. Eur J Surg Oncol 2005; 31:833-9.

21. Lagios MD, Margolin FR, Westdahl PR, Rose MR. Mammographically detected ductal carcinoma in situ. Frequency of local recurrence following tylectomy and prognostic effect of nuclear grade on local recurrence. Cancer 1989; 63:618-24. 
22. Boyages J, Delaney G, Taylor R. Predictors of local recurrence after treatment of ductal carcinoma in situ: a meta-analysis. Cancer 1999; 85:616-28.

23. Kerlikowske K, Mollarino A, Cha I, et al. Characteristics associated with recurrence among women with ductal carcinoma in situ treated by lumpectomy. $J$ Natl Cancer Inst 2003; 95:1692-1702.

24. Walker RA, Dearing SJ, Brown LA. Comparison of pathological and biological features of symptomatic and mammographically detected ductal carcinoma in situ of the breast. Hum Pathol 1999; 30:943-8.

25. Idvall I, Andersson C, Fallenius G, et al. Histopathological and cell biological factors of ductal carcinoma in situ before and after the introduction of mammographic screening. Acta Oncol 2001; 40:653-9.

26. Evans AJ, Pinder SE, Ellis IO, Wilson AR. Screen detected ductal carcinoma in situ (DCIS): overdiagnosis or an obligate precursor of invasive disease? J Med Screen 2001; 8:149-51.

27. Kessar P, Perry N, Vinnicombe SJ, Hussain HK, Carpenter R, Wells CA. How significant is detection of ductal carcinoma in situ in a breast screening programme? Clin Radiol 2002; 57:807-14.

28. Ho GH, Calvano JE, Bisogna M, et al. In microdissected ductal carcinoma in situ, Her-2/neu amplification, but not p53 mutation, is associated with high nuclear grade and comedo histology. Cancer 2000; 89:2153-60.

29. Mack L, Kerkvliet N, Doig G, O’Malley FP. Relationship of a new histological categorization of ductal carcinoma in situ of the breast with size and the immunohistochemical expression of p53, c-erbB-2, bcl-2, and ki-67. Hum Pathol 1997; 28:974-9.

30. Leal CB, Schmitt FC, Bento MJ, Maia NC, Lopes CS. Ductal carcinoma in situ of the breast. Histologic categorization and its relationship to ploidy and immunohistochemical expression of hormone receptors, p53, and c-erbB-2 protein. Cancer 1995; 75:2123-31.

31. Boland GP, Knox WF, Bundred NJ. Molecular markers and therapeutic targets in ductal carcinoma in situ. Microsc Res Tech 2002; 59:3-11. 